\title{
OS CONTEÚDOS DE BIOLOGIA CELULAR NO EXAME NACIONAL DO ENSINO MÉDIO - ENEM
}

\author{
Julio Sergio dos SAntos*1 \\ ÂNGelo Luiz CoRTelazzo**
}

Recebido: 4 jan. 2012

Aprovado: 2 jul. 2012

* Instituto de Biologia, Universidade Estadual de Campinas. Campinas, SP, Brasil.

Contato com o autor: juliocezasantos@yahoo.com.br

**Departamento Biologia Celular. Instituto de Biologia. Universidade Estadual de Campinas. Campinas, SP, Brasil.

Contato com o autor: alcortelazzo@hotmail.com

Resumo: O Exame Nacional do Ensino Médio vem se tornando um exame de extrema importância para avaliar os egressos do ensino médio. Isso porque ele seleciona estudantes para o ensino superior e contempla, em sua fundamentação a elaboração de competências e habilidades relacionadas a esse nível de ensino. O nosso estudo analisou a forma das questões exigidas pelo ENEM, bem como as habilidades avaliadas neste exame. De um total de 900 questões de diversas disciplinas, observamos 35 que continham algum conteúdo de biologia celular. Algumas dessas perguntas estavam associadas a diferentes disciplinas do ensino médio ou podiam exigir uma forte memorização de conteúdos específicos. Também foram encontradas questões que enfatizavam a resolução de problemas contextualizados, relacionados a fenômenos biológicos, mitigando, desse modo, o enfoque conteudista ou de conteúdo primado na aprendizagem no ensino médio.

Palavras-chave: Biologia celular. Avaliação. Aprendizagem. Habilidades.

\section{THE CELL BIOLOGY CONTENT IN THE EXAME NACIONAL DO ENSINO MÉDIO - ENEM}

Abstract: The Exame Nacional do Ensino Médio (ENEM) has become extremely important to evaluate high school graduates. This is because it is used to select students for college and it evaluates their skills and competencies acquired in high school. We analyzed the formulation of questions, as well as the skills assessed in this exam. We observed that, out of the sample of 900 questions of several subjects, 35 included cell biology content. Some questions were associated with other high school subjects or could require a stronger content specific memorization. However, most questions emphasized problem solving associated with biological phenomena. This type of emphasis on problem solving questions is not recurrent in most high schools, as students are usually encouraged to memorize extensive content.

Key words: Cell biology. Evaluate. Learning. Skills.

\section{INTRODUÇÃO}

\subsection{ENEM}

O Exame Nacional do Ensino Médio (ENEM), coordenado e aplicado pelo Ministério da Educação (MEC) e pelo Instituto Nacional de Estudos e Pesquisas Educacionais Anísio Teixeira (INEP), é considerado um exame que traz

1 Agradecimentos: Salientando que esse artigo faz parte de uma pesquisa de Mestrado, agradecemos ao CAPES e CNPq, pelo incentivo e apoio financeiro, e ao programa de Pós-Graduação em Biologia Celular e Estrutural, UNICAMP. Também agradecemos à Pedagoga Regina Célia dos Santos e à Profa. Dra. Lenita Tallarico, que fizeram contribuições valiosas para a redação desse artigo. 
características de uma avaliação classificatória e diagnóstica, que compara e mede resultados, expressando a pontuação dos alunos em faixas de desempenho (ZANCHET, 2003).

Diversos autores elaboraram ideias sobre o ENEM, discorrendo sobre sua função, as matrizes pedagógicas que o concebem e analises sobre seus desdobramentos no sistema brasileiro. Mas de maneira geral o Exame Nacional para o Ensino Médio, é constituído de testes que medem conteúdos aprendidos no contexto escolar com a intencionalidade de verificar a aplicação dos mesmos nas diferentes situações da vida.

Soares e Nascimento (2011) afirmam que é uma avaliação que não tem como foco somente o conteúdo de modo abstrato, pois avalia habilidades cognitivas e sua aplicabilidade no cotidiano do estudante.

O ENEM hierarquiza os saberes e seleciona os alunos (MILDNER; SILVA, 2002a) por meio de avaliações contendo questões de múltipla escolha e redações, as quais são fundamentadas em uma matriz de competências e habilidades atribuídas durante o processo de ensino e aprendizagem do aluno de ensino médio. Segundo Primi et al (2001), essa matriz, presente na concepção do ENEM, foi criada a partir das ideias da corrente desenvolvimentista de Piaget. Essa corrente foi discutida por Perrenoud (1997), Machado (2005) e Macedo (1999). Sua matriz diagnosticada como construtivista (GOMES, 2005), é correspondente às possibilidades totais da cognição humana na fase de desenvolvimento próprio aos participantes do ENEM (BRASIL, 1999a, p. 9). Oito competências e trinta habilidades exigidas no ENEM compõem a matriz de competências de ciência da natureza. As habilidades são definidas como um "saber-fazer" (BRASIL, 2000, p. 5).

Documentos oficiais, como os Parâmetros Curriculares Nacionais para o Ensino Médio - PCNEM (BRASIL, 1999b) e as Orientações Educacionais Complementares aos Parâmetros Curriculares Nacionais - PCN+ (BRASIL, 2002) demonstram diretrizes para o ensino médio, ou seja, orientam e incentivam a aplicação de competências e habilidades associadas às diversas disciplinas escolares. Assim, o ENEM, que avalia o egresso do ensino médio, é aplicado com base nas diretrizes descritas nestes documentos. O documento básico do ENEM (BRASIL, 2002, p. 5) ressalta a importância desse exame, proposto no final do ensino médio, ser um instrumento de avaliação que afere as competências importantes ao exercício da cidadania.

As competências são necessariamente articuladas com a vida cotidiana do egresso do ensino médio, o que implica na importância da contextualização para a elaboração da prova deste exame. Sass e Minhoto (2010) mencionam 
que devido às novas demandas da sociedade, no que se refere à formação do indivíduo, implica a articulação da esfera educacional à esfera do trabalho.

Outra ideia é apresentada por Minhoto (2008) que alega que este exame de larga escala não incentiva a autonomia escolar, sua função de selecionar os jovens para o ensino superior não contribui para a formação de indivíduos críticos e criativos, tendo em vista o modo como opera o sistema educacional brasileiro. $\mathrm{O}$ que tem gerado, por meio de sua função e selecionar jovens, o aumento da procura por cursos preparatórios específicos para o exame, mostrando, desta maneira, que a formação oferecida por boa parte das escolas de ensino médio, principalmente pelas escolas públicas, não é suficiente para o aluno ingressar numa faculdade (CORTELAZZO, 2003; SANTOS, 2008).

Para Franco Júnior (2003), o ENEM tem a vantagem de focalizar dois pontos importantes, a saber: a) a ênfase na leitura e na compreensão de textos ao invés da sobrevalorização dos aspectos normativos da linguagem; b) o enfoque na resolução de problemas ao invés da supervalorização dos detalhes do extenso currículo do ensino médio.

Além da ênfase na leitura e da resolução de problemas, o ENEM não privilegia o isolamento das disciplinas do Ensino Médio, e sim a integração entre os conteúdos das diversas disciplinas presentes nas propostas curriculares das escolas brasileiras (SILVA SOARES, 1999). Assim, ao atender às características interdisciplinares, o exame não fragmenta os conteúdos das matérias específicas - através das quais o aluno demonstra conhecimentos isolados - mas visa a avaliar as competências e habilidades adquiridas ao longo de todo o curso médio, independentemente das disciplinas cursadas (SILVA SOARES, 1999).

Segundo Cavalcante et al (2006) o ENEM está organizado em três eixos: a contextualização, a situação problema e a interdisciplinaridade. A problematização além de ser um eixo importante para esse exame é uma condição primária para a aprendizagem significativa, a qual incorpora a teoria do construtivismo. Gomes e Borges (2009) afirmaram que o exame supracitado segue uma referência teórica construtivista.

A contextualização, a problematização e a interdisciplinaridade compõem as investigações deste estudo para os conteúdos de biologia celular, no qual é analisada sua forma em que se estabelece relacionados ao cotidiano social, também identificando a existência da interdisciplinaridade e relacionando se ocorre o incentivo a resolução dos testes baseado no raciocínio de problemas ligados a fenômenos biológicos. É claro que por serem conteúdos abstratos (PALMERO, 2003) para os alunos ou egresso do ensino médio, necessitam ser 
ensinados de forma ativa, em que o estudante analisa e raciocinam as informações apresentadas nesse ensino (KITCHEN et al, 2007; SANTOS, 2008).

A investigação deste nosso estudo é a relação das habilidades e competências aos conteúdos de biologia celular, na forma de averiguar como se dá a associação das habilidades com esse conhecimento. Também é analisado se nas perguntas desse exame enfatizam mais a reprodução de conceitos do que a resolução de problemas contextualizados e interdisciplinares.

Os conteúdos de biologia celular exigidos no ENEM, os quais são os objetos da discussão deste estudo, compreendem desde a identificação dos seres vivos, a exemplo de células, suas relações e particularidades, até conteúdos mais complexos, como a clonagem, a biotecnologia: aplicações de tecnologias relacionadas ao DNA, às investigações científicas, à determinação da paternidade, à investigação criminal e à identificação de indivíduos. Ademais, há no exame, questões que exigem reflexão sobre aspectos éticos relacionados ao desenvolvimento biotecnológico (BRASIL, 2009). E este conteúdo ganha mais importância para sua compreensão na medida em que são discutidos na mídia e investigados de forma crescente na área cientifica, como por exemplo, os temas da clonagem e as células-tronco, ambas debatidas em fóruns jornalísticos e pesquisa acadêmica, a sociedade civil como um todo, o que por sua vez contribui elaboração das questões de maneira contextualizada.

A biologia celular é relevante para entender a dinâmica da vida, no seu conceito mais simples e basal na compreensão da particularidade de cada indivíduo, ou seja, o fundamento de que todo ser vivo é formado por células assim, é um conteúdo relevante para a formação do egresso do ensino médio. Portanto o estudo ora proposto se justifica na medida em que se propõe a analisar as interfaces contidas no exame: conteúdo e questões do cotidiano, recursos cognitivos exigidos, já que o ENEM como ingresso dos estudantes no ensino superior tem se consolidado no sistema brasileiro de educação e pautando a organização dos conteúdos do ensino médio.

\section{METODOLOGIA}

Os recursos metodológicos utilizados para este estudo envolveram a análise de questões formuladas para o Exame Nacional do Ensino Médio dos anos de 1998 a 2011, os requisitos cognitivos para respondê-las e uma analise das habilidades da Matriz de Referências (BRASIL, 2009).

A análise das questões do ENEM foi selecionada a partir das perguntas que obtivessem a exigência dos conteúdos de biologia e que necessariamente 
continham algum conteúdo de biologia celular, como a divisão celular e a replicação do DNA. Outras questões que não continha esse conteúdo para este estudo, mesmo que contivessem conteúdos relacionados à biologia não foram analisadas. A seleção das questões contou com a participação de três professores avaliadores com formação biologia, um dos quais com mestrado na área de concentração em biologia celular. Todas as provas investigadas nesse estudo foram de cores amarelas.

Para analisá-las propomos três tipos de exigência de conteúdos nas questões, os quais poderiam requerer dos egressos do ensino médio, além do exercício da memorização, a interpretação e a análise do conteúdo de biologia celular propriamente. Para esses tipos de perguntas, identificamos com números: 1, 2 e 3. Chamamos esses números de escores ao longo do texto. Esses números, aqui utilizados, procuram, de acordo com sua crescente numeração, sistematizar a cada nível de pensamento os processos mentais exigidos nas questões. Esses processos mentais podem ser: o reconhecimento ou a associação do conteúdo, a explicação ou a transposição de fenômenos e conceitos e, por fim, a síntese ou a predição de dados experimentais (SANT'ANNA, 1995).

Além dessa análise identificada e sistematizada, foram analisadas as habilidades da Matriz de Referências (BRASIL, 2009) propostas em cada exercício contendo algum conteúdo de biologia celular. Essa análise procurou encontrar alguma habilidade da Matriz relacionada constantemente com as questões contendo esse conteúdo. Também foi investigada a forma do conteúdo relacionado com a habilidade, de maneira a encontrar na pergunta a requisição: apenas da memorização de conceitos, o conhecimento prévio e o incentivo a resolução de problemas. Essa análise foi realizada com auxílio de dois professores avaliadores de biologia, os quais relacionaram os conteúdos exigidos nas questões com as habilidades propostas nas oito competências propostas na nova Matriz de referências.

\subsection{Aplicação da sistematização - escores}

As questões objetivas de múltipla escolha, segundo Sant'Anna (1995), são aplicadas para reconhecer o conteúdo, em que o aluno organiza os elementos apresentados à resposta ou os reconhece.

As questões dos exames do ENEM são de múltipla escolha e propõem a contextualização do tema da biologia celular relacionada a fenômenos biológicos; a interpretação de gráficos; a exigência de conteúdos memorizados; e o conteúdo específico da biologia celular. Para construir os parâmetros dos 
escores, os quais são descritos abaixo, foram consultados por três professores de biologia e uma pedagoga.

Escore 1 - Nesse escore, as questões apenas reconheciam o conteúdo de biologia celular, o qual não estava relacionado com outros conteúdos e não apresentava contextualização com algum fenômeno biológico que poderia estar associado com o cotidiano do aluno de ensino médio.

Escore 2 - Essas questões buscavam a interpretação de dados de tabelas ou quadros e a comparação desses dados. Além disso, as questões apresentavam conteúdos de biologia celular relacionados com fenômenos biológicos que, por sua vez, poderiam estar associados ao cotidiano do egresso do ensino médio e a temas atuais da nova biotecnologia, tais como a clonagem e as células-tronco. Também atribuímos o escore 2 quando as questões relacionavam o conteúdo de biologia celular com conteúdos de outros temas da biologia: a genética, a microbiologia, a embriologia, botânica, etc.

Escore 3 - Nesse escore, as questões apresentavam dados da biologia celular em gráficos relacionados com algum conteúdo diferente da biologia celular ou, então, quando relacionados com fenômenos biológicos que poderiam estar associados com o cotidiano do aluno do ensino médio ou associados com a biotecnologia. É importante destacar que, nesse tipo de questão, o aluno reorganiza o conteúdo, ampliando e explorando novas associações.

\section{RESULTADOS E DISCUSSÃO}

\subsection{As questões e os escores - Frequência e escores das questões contendo algum conteúdo de biologia celular.}

As 35 questões da tabela 1 correspondem a um universo de 900 questões exigidas no ENEM de 1998 a 2011. Cabe salientar que no ENEM de 1998 a 2008 foram exigidas 63 questões de múltipla escolha, das mais diversas disciplinas escolares. Já nos ENEM de 2009 a 2011, foram exigidas 45 questões de Ciências da Natureza (compreendendo as disciplinas de Física, Biologia e Química).

Ao analisar os escores aplicados nas provas ENEM, notou-se que das 35 questões encontradas no ENEM contendo algum conteúdo de biologia celular, 27 questões $(77,14 \%)$ contextualizavam com algum fenômeno biológico associado com o cotidiano do aluno ou com temas da biotecnologia, da genética e da microbiologia. 
Tabela 1 - Frequência e escores das questões contendo conteúdo de biologia celular no ENEM de 1998 a 2011.

\begin{tabular}{ccc}
\hline Ano & $\begin{array}{c}\text { Número de } \\
\text { questões }\end{array}$ & $\begin{array}{c}\text { Escores } \\
\text { obtidos por } \\
\text { questão }\end{array}$ \\
\hline 1998 & 2 & 2 e 2 \\
\hline 1999 & 2 & 2 e 2 \\
\hline 2000 & 2 & 2 e 2 \\
\hline 2001 & 0 & - \\
\hline 2002 & 3 & 3,3 e 3 \\
\hline 2003 & 3 & 2,2 e 2 \\
\hline 2004 & 2 & 2 e 2 \\
\hline 2005 & 2 & 2 e 2 \\
\hline 2006 & 2 & 2 e 2 \\
\hline 2007 & 3 & 2,2 e 2 \\
\hline 2008 & 4 & $2,2,2$ e 2 \\
\hline 2009 & 2 & 2 e 2 \\
\hline 2009 & 1 & 3 \\
\hline 2010 & 3 & 2 e 2 \\
\hline 2010 & 1 & 3 \\
\hline 2011 & 4 & $2,2,2$ e 2 \\
\hline Total & 35 & \\
\hline
\end{tabular}

Fonte: Autoria própria

Nesta contextualização de conteúdos de biologia celular associados a fenômenos biológicos, sempre se exigia questões com incentivo ao raciocínio através da resolução de problemas.

Além disso, as questões de biologia celular continham tabelas, gráficos e análise de fenômenos. Isso configurou que essas perguntas incentivaram a resolução de problemas. Esse incentivo corroborou as conclusões obtidas por Fini (2005). É válido destacar que o incentivo à resolução de problemas não é exclusivo dos conteúdos de biologia celular, pois Amorim (2009) também diagnosticou esse incentivo nas questões de matemática do ENEM.

Algumas questões exigiram a interpretação de novos conceitos da biologia, como a clonagem e os transgênicos. De maneira particular, as questões do exame do ano de 2002, todas receberam o escore 3 (tabela 1), pois essas questões continham, em seus enunciados, dados na forma de gráficos e conteúdos com outros subtemas da biologia, como a genética. 
Apesar de nossa pesquisa analisar apenas as questões contendo algum conteúdo de biologia celular, observamos que a maioria delas não exige alto grau de abstração ou análise mais complexa desse conteúdo, o que confirma os resultados obtidos por Fini (2005), o qual afirmou que a maioria das questões exigidas no ENEM são itens fáceis e médios nas suas resoluções.

\subsection{Habilidades e interdisciplinaridade}

Inicialmente, a principal competência (BRASIL, 2009) exigida nas questões contendo algum conteúdo de biologia celular foi a competência 4 (tabela 3 ), pois se notou que muitas questões envolviam a compreensão e o reconhecimento de mecanismos de transmissão da vida, como o DNA, e a interpretação de fenômenos relacionados a particularidades dos indivíduos, principalmente o ser humano. Outra competência importante, não tanto quanto a competência 4, foi a de número 8 (tabela 3), a qual o estudante se apropriava dos conhecimentos de biologia em situações problemas e planejava intervenções. Essa competência é importante para o estudante, na qual ele compreende conceitos de biologia e os utiliza na análise de um determinado fenômeno biológico, fazendo relações com o ambiente. Esse fenômeno biológico pode ter aspectos relacionados com o cotidiano do aluno.

As questões as quais contêm alguns conteúdos de biologia celular envolveram algumas habilidades (tabela 2) da nova matriz de referência do ENEM (BRASIL, 2009).

Em seguida, estão destacadas três questões contendo conteúdos de biologia celular e as habilidades envolvidas nessas questões.

Questão 18 (ENEM - 2003):

Na embalagem de um antibiótico, encontra-se uma bula que, entre outras informações, explica a ação do remédio do seguinte modo:

"O medicamento atua por inibição da síntese proteica bacteriana"

Essa afirmação permite concluir que o antibiótico

A) impede a fotossintese realizada pelas bactérias causadoras da doença $e$, assim, elas não se alimentam e morrem.

B) Altera as informações genéticas das bactérias causadoras da doença, o que impede manutenção e reprodução desses organismos.

C) Dissolve as membranas das bactérias responsáveis pela doença, o que dificulta o transporte de nutrientes e provoca a morte delas. 
Tabela 2 - Questões do ENEM (1998-2011) relacionadas às habilidades da nova Matriz de Referência do ENEM.

\begin{tabular}{|c|c|c|c|c|c|}
\hline Ano & № Questão & Habilidades & Ano & $\begin{array}{l}\text { № } \\
\text { Questão }\end{array}$ & Habilidades \\
\hline \multirow[b]{2}{*}{1998} & \multirow[b]{2}{*}{31} & \multirow[b]{2}{*}{13,15} & 2006 & 10 & 15,16 e 17 \\
\hline & & & 2007 & 13 & $14,15,17$ e 24 \\
\hline 1998 & 32 & 13,15 e 17 & 2007 & 15 & 14 e 15 \\
\hline 1999 & 28 & 13,15 e 17 & 2007 & 33 & $13,14,15$ e 16 \\
\hline 1999 & 29 & 13,15 e 17 & 2008 & 43 & $14,15,17$ \\
\hline 2000 & 2 & $15,17,18$ e 24 & 2008 & 44 & 2,14 e 30 \\
\hline 2000 & 48 & 14 e 30 & 2008 & 52 & $13,14,15$ e 17 \\
\hline 2002 & 52 & $13,15,16$ e 17 & 2008 & 53 & 13 e 14 \\
\hline 2002 & 60 & 14,16 e 17 & 2009 & 3 & 14,17 e 25 \\
\hline 2002 & 61 & 14,16 e 17 & 2009 & 30 & 14,17 e 25 \\
\hline 2003 & 18 & 14 e 30 & 2009 & 40 & $14,15,17,18$ e 25 \\
\hline 2003 & 19 & 14 e 15 & 2010 & 49 & 14,15 e 25 \\
\hline 2003 & 20 & 7,14 e 29 & 2010 & 63 & 14,15 e 17 \\
\hline 2004 & 11 & 14 e 17 & 2010 & 65 & $14,15,17$ e 28 \\
\hline 2004 & 57 & 13 e 17 & 2011 & 49 & 14 e 15 \\
\hline 2005 & 11 & 14,15 e 17 & 2011 & 58 & 14 e 17 \\
\hline 2005 & 41 & $14,17,18$ e 29 & 2011 & 62 & $13,14,15$ e 17 \\
\hline 2006 & 47 & 14,17 e 30 & 2011 & 73 & 14 e 17 \\
\hline
\end{tabular}

Fonte: Autoria própria

\section{Tabela 3 - Algumas Competências e Habilidades da nova Matriz de Referência relacionadas ao conteúdo de biologia celular.}

\begin{abstract}
Competências
Competência 4: Compreender interações entre organismos e ambientes, em particular aquelas relacionadas à saúde humana, relacionando conhecimentos cientíicos, aspectos culturais e características individuais.
\end{abstract}

Habilidades

H13: Reconhecer mecanismos de transmissão da vida, prevendo ou explicando a manifestação de características dos seres vivos.

H14: Identificar padrões em fenômenos e processos vitais dos organismos, como manutenção do equilíbrio interno, defesa, relações com o ambiente, sexualidade, entre outros.

H15: Interpretar modelos e experimentos para explicar fenômenos ou processos biológicos em qualquer nível de organização dos sistemas biológicos.

H16: Compreender o papel da evolução na produção de padrões, processos biológicos ou na organização taxonômica dos seres vivos.

Fonte: BRASIL. Ministério da Educação. Secretaria de Educação Média e Tecnológica. Matriz de referência para o ENEM. Brasília: INEP, 2009. 
D) elimina os vírus causadores da doença, pois não conseguem obter as proteinas que seriam produzidas pelas bactérias que parasitam.

E) interrompe a produção de proteína das bactérias causadoras da doença, o que impede sua multiplicação pelo bloqueio de funções vitais.

A questão 18 pareceu, principalmente, contemplar a habilidade 14, a qual exige a interpretação de fenômenos biológicos e processos vitais. Essa habilidade está associada à competência 4 (tabela 3). Contudo, para responder de modo assertivo se faz necessário a evocação de conteúdos que foram transmitidos por professores ou matérias didáticos do ensino médio. Essa evocação é corroborada pelos dados apresentados por Mildner e Silva (2002b). Ademais, o enunciado dessa questão continha o conteúdo contextualizado com a realidade de muitos egressos: o uso de antibióticos para combater infecções bacterianas.

Questão 47 (ENEM - 2006):

Dieta de engorda (em 30 anos, a alimentação piorou muito)

Fonte: ENEM (2006)

\begin{tabular}{|c|c|c|c|}
\hline \multicolumn{4}{|c|}{ Aumento no consumo - por família } \\
\hline Biscoitos $400 \%$ & Refrigerantes $400 \%$ & Salsichas e linguiças $300 \%$ & Refeições prontas $80 \%$ \\
\hline \multicolumn{4}{|c|}{ Diminuição no consumo - por família } \\
\hline Ovos $84 \%$ & Peixes 50\% & Feijão e leguminosas $30 \%$ & Arroz 23\% \\
\hline
\end{tabular}

A partir desses dados, foram feitas as afirmações abaixo:

I. As famílias brasileiras, em 30 anos, aumentaram muito o consumo de proteinas e grãos, que, por seu alto valor calórico, não são recomendáveis. II $O$ aumento do consumo de alimentos muito calóricos deve ser considerado indicador de alerta para a saúde, já que a obesidade pode reduzir a expectativa de vida humana. III Doenças cardiovasculares podem ser desencadeadas pela obesidade decorrente das novas dietas alimentares. É correto apenas o que se afirma em
AI.
B II.
C III.
D I e II.
E II e III.

O enunciado da questão 47 apresentou o conteúdo na forma tabela. Assim, para ser respondido, necessitou de habilidades como a 17. Além disso, o conteúdo envolvido no enunciado pareceu requerer a habilidade 30 do egresso do ensino médio, pois exigiu a compreensão do tema da alimentação saudável, o 
qual é importante não somente para um indivíduo, mas para o coletivo, como a família brasileira. A habilidade 14, requerida no enunciado, não pareceu estar envolvida em um único fenômeno ou único processo vital, mas ao conjunto de vários fenômenos: isso porque o egresso, diante desse enunciado, tem que se lembrar de conceitos, como a síntese de proteínas, o colesterol de baixa densidade, colesterol de alta densidade, a importância dos lipídios para o corpo humano etc.

Questão 43 (ENEM - 2008):

Defende-se que a inclusão da carne bovina na dieta é importante, por ser uma excelente fonte de proteinas. Por outro lado, pesquisas apontam efeitos prejudiciais que a carne bovina traz à saúde, como o risco de doenças cardiovasculares. Devido aos teores de colesterol e de gordura, há quem decida substitui-la por outros tipos de carne, como a de frango e a suina. O quadro abaixo apresenta o colesterol em diversos tipos de carne crua e cozida.

\begin{tabular}{l|c|c}
\hline \multirow{2}{*}{ Alimento } & \multicolumn{2}{|l}{ Colesterol $\mathbf{m g} / \mathbf{1 0 0 g}$} \\
\cline { 2 - 3 } & Cru & Cozido \\
\hline Carne de frango branca sem pele & 58 & 75 \\
\hline Carne de frango escura sem pele & 80 & 124 \\
\hline Pele de frango & 104 & 139 \\
\hline Carne suína (bisteca) & 49 & 97 \\
\hline Carne suína (toucinho) & 54 & 56 \\
\hline Carne bovina (contrafilé) & 51 & 66 \\
\hline Carne bovina musculo & 52 & 67 \\
\hline
\end{tabular}

Com base nessas informações, avalie as afirmativas a seguir:

I O risco de ocorrerem doenças cardiovasculares por ingestões habituais da mesma quantidade de carne é menor se esta for carne branca de frango do que se for toucinho

II Uma porção de contrafilé cru possui, aproximadamente, $50 \%$ de sua massa constituída de colesterol.

III A retirada da pele de uma porção cozida de carne escura de frango altera a quantidade de colesterol a ser ingerida.

IV A pequena diferença entre os teores de colesterol encontrados no toucinho cru e no cozido indica que esse tipo de alimento é pobre em água.

É correto apenas o que se afirma em:
a) I e II
b) I e III
c) II e III
d) II e IV
e) III e IV 
O enunciado dessa pergunta procurou fornecer os dados na forma de tabela. As habilidades principais foram: 14, 15 e 17. A interpretação dos dados foi importante para a resolução. Além disso, esse enunciado não evoca muitos conteúdos do egresso, mas exige apenas a interpretação de um tema, o colesterol, que é bem recorrente nas fontes da mídia e que pode ser discutido em alguns fatos do dia-a-dia, como aquele quando são observados os resultados do exame de sangue.

Questão 65 (ENEM - 2010):

Um ambiente capaz de asfixiar todos os animais conhecidos do planeta foi colonizado por pelo menos três espécies diferentes de invertebrados marinhos. Descobertos a mais de $3000 \mathrm{~m}$ de profundidade no Mediterrâneo, eles são os primeiros membros do reino animal a prosperar mesmo diante da ausência total de oxigênio. Até agora, achava-se que só bactérias pudessem ter esse estilo de vida. Não admira que os bichos pertençam a um grupo pouco conhecido, o dos loriciferos, que mal chegam a 1,0 mm. Apesar do tamanho, possuem cabeça, boca, sistema digestivo e uma carapaça. A adaptação dos bichos à vida no sufoco é tão profunda que suas células dispensaram as chamadas mitocôndrias.

Que substâncias poderiam ter a mesma função do $\mathrm{O}_{2}$ na respiração celular realizada pelos loriciferos:
A) $\mathrm{SeCH}_{4}$
B) $\mathrm{S}$ e $\mathrm{NO}_{3}^{-}$
C) $\mathrm{H}_{2}$ e $\mathrm{NO}_{3}^{-}$
D) $\mathrm{CO}_{2}{\mathrm{e} \mathrm{CH}_{4}}$
E) $\mathrm{H}_{2}$ e $\mathrm{CO}_{2}$

A questão 65 (ENEM - 2010) exigiu as habilidades 14, 15, 17 e 28, conforme apontadas na tabela 2. Contudo, essa assertiva demandou, de maneira muito particular, a interpretação de um fenômeno biológico de um organismo, tornando a exigência muito específica. Além disso, para resolver essa pergunta, se fez necessário o uso de conhecimentos químicos, como o a compreensão de que o oxigênio é um agente oxidante. Essa forma de exigência não está de acordo com os documentos oficiais do ENEM, os quais incentivam essencialmente a interpretação de situações problemas em vez da sobrevalorização dos conteúdos.

Assim, é possível observar que os enunciados das questões sempre envolveram mais de uma habilidade, como já fora exemplificado nas questões acima e diagnosticado na tabela 2. Ademais, essas questões exigiram, parcialmente, $o$ domínio de uma determinada habilidade. Por exemplo, a questão 65 (ENEM - 
2010), que exigiu a compreensão do fenômeno da respiração celular (o qual é conteúdo da biologia celular), requereu a habilidade 14, quanto à identificação da respiração celular, como fenômeno vital, mas não como um fenômeno de sexualidade ou de defesa do organismo.

Entretanto, essa exigência parcial não foi exclusiva das habilidades, pois a competência 4 (tabela 3), por sua vez, foi muito abrangente quanto à exigência dos conteúdos de biologia celular. Nessa competência, exigiu-se a compreensão da particularidade da saúde humana e as interações entre os organismos e seu ambiente. Isso pareceu não propor a real compreensão para os conteúdos de biologia celular, que é a particularidade dos seres vivos e seus mecanismos intracelulares. A principal habilidade que contemplou essa particularidade é a 13, uma vez que parece haver o reconhecimento dos mecanismos intracelulares quando postula a importância dos mecanismos de transmissão da vida. Essa exigência parcial das habilidades e competências pode ser uma tentativa da nova Matriz de Referência do ENEM (BRASIL, 2009) de englobar ou abranger os diferentes conteúdos das Ciências da Natureza, a qual contém três disciplinas do ensino médio: biologia, química e física. Gomes (2005) ao analisar a prova objetiva do ENEM 2001, ressaltou não ter encontrado relação direta das habilidades com os processos cognitivos mais voltados aos conteúdos escolares. Essa investigação se deu quando a matriz de referência do ENEM continha 5 competências e 21 habilidades.

Os exames referentes ao ENEM, de 2009 a 2011, exigiram 180 questões, enquanto nas provas de 1998 a 2008, apenas 63 questões. Juntamente a isso, houve o aumento do número de competências e habilidades na nova Matriz de Referencias (BRASIL, 2009): de 5 competências para 8 competências e de 21 habilidades para 30 habilidades. Essa mudança parece ter influenciado a exigência da especificidade dos conteúdos, como já notado na questão 65 (ENEM - 2010).

As principais habilidades requeridas nas questões que envolveram algum conteúdo de biologia celular foram: 13, 14 e 15, as quais são destacadas na tabela 2. Essas questões exigiam do aluno o reconhecimento de conteúdos relacionados à identificação e fenômenos relacionados ao particular do indivíduo ou do ser vivo, ou seja, fenômenos que ocorrem nas células dos seres vivos. Também exigiam o reconhecimento de mecanismos que transmitem a vida. Em relação a essas habilidades exigidas nas questões, primam pelo reconhecimento, relacionamento e identificação dos conhecimentos da biologia celular, em vez do reconhecimento dos conteúdos associado a uma análise, em que o egresso do ensino médio pode reorganizar os conteúdos, ampliar ou explorar 
novas associações. Esse tipo de associação é mais requerente nas habilidades vinculadas às competências 7 e 8 (tabela 3). É claro que os conteúdos de biologia celular são relacionados à particularidade do ser vivo, os quais são distante do mundo palpável do aluno e apenas compreendidos com auxílio de um microscópio, o que pode dificultar a associação e análise desse conteúdo juntamente com outros fenômenos biológicos de maior abrangência. Contudo, torna-se importante a associação dessa particularidade com outros fenômenos biológicos que existem fora da célula, como aqueles que agem nos tecidos, evitando a fragmentação do conhecimento.

Como a biologia celular apresenta vários conceitos e termos, ambos abstratos (PALMERO, 2003), torna-se necessária uma aprendizagem efetiva (KITCHEN et al, 2007; SANTOS, 2008). Esse tipo de aprendizagem pode estar relacionado ao incentivo da resolução de problemas relacionados aos fenômenos biológicos, justamente como o proposto na maioria das questões do ENEM. Isso permite ao estudante a possibilidade de empregar, de fato, o que aprendeu durante a sua formação, bem como suas reflexões sobre a temática da biologia celular.

A relação dos conteúdos de biologia celular com fenômenos biológicos é importante para que o aluno conheça a aplicabilidade do conceito, pois, na quarta competência de ensinar proposta por Perrenoud (2000), é importante envolver os alunos, fazendo uma relação entre a aprendizagem e o trabalho (vida cotidiana). $\mathrm{O}$ envolvimento construído através desta relação passa pelo interesse prévio de conhecer os conteúdos da disciplina, surgindo o desejo de saber. Desse modo, pode-se relacionar essa competência de Perrenoud (2000) com os conteúdos de biologia celular: por exemplo, fenômenos biológicos e conceitos da biotecnologia (vitaminas que combatem o envelhecimento, clonagem, células tronco, etc.), os quais sempre são noticiados na mídia, entretanto o estudante pode não conhecer os mecanismos e conceitos biológicos envolvidos nesses fenômenos. Sendo assim, caso se mantenha uma aprendizagem não relacionada com a vida cotidiana/trabalho, os alunos continuarão a observar notícias midiáticas, contendo temas como a clonagem, célula tronco etc., sem compreender a ciência envolvida nesses fenômenos e conceitos.

A contextualização sociocultural (BRASIL, 2002) também foi presente nas questões desse conteúdo. De acordo com o PCN+ (BRASIL, 2002), a contextualização é vista como uma competência geral. Ela permitiu integrar os conteúdos de biologia celular com o conhecimento científico-tecnológico, como a clonagem e outros temas da biotecnologia.

O incentivo ao raciocínio, à interpretação de fenômenos e à contextualização dos conteúdos, foram muito presentes nas questões envolvendo os conteúdos de 
biologia celular. Por outro lado, é interessante observar que essas habilidades e contextualizações não são exclusivas desses conteúdos, já que o raciocínio, habilidade essencial na resolução de problemas foi muito exigido nas questões de matemática do ENEM de 1999 (BRITO et al, 2000).

As 35 questões investigadas nesse trabalho exigiam principalmente a interpretação, o que foi diagnosticado através do estudo dos escores 3. Confirma-se, desse modo, que as questões desse exame não exigem apenas o reconhecimento do conteúdo, mas também a sua interpretação, juntamente com a habilidade do raciocínio na resolução de problemas. Salientando a importância dessa habilidade, Gomes e Borges (2009) analisaram as habilidades cognitivas na prova do ENEM 2001 e diagnosticaram a exigência do raciocínio nas questões. Outros autores que encontram essa habilidade no ENEM foram Brito et al (2000), os quais analisaram as questões de matemática do ano de 1999. Assim, sabendo do constante uso dessa habilidade nas questões do ENEM que envolvem problemas, nota-se que esse exame a princípio, na teoria, implica uma forte ênfase na inteligência fluida. A inteligência fluida, segundo Gomes (2005), caracteriza-se como um conjunto de processos cognitivos relacionados à capacidade de lidar com as situações abstratas, raciocinar e resolver problemas. Entretanto, Gomes (2005) menciona que as questões da prova do ENEM - 2001 exigiram processos cognitivos relacionados com a mobilização de esquemas prévios de conhecimento, articulados de modo a organizar as informações dos enunciados e formar inferências aos problemas propostos. Assim, esse autor relaciona os fatores cognitivos: inteligência cristalizada, o fator geral e o pensamento visual às provas do ENEM.

Dentro dessa análise da psicometria, Fini (2005) afirma que as questões desse exame nacional não enfatizam principalmente a cognição da memória, o que ressalta a importância do emprego do raciocínio na resolução de problemas nas questões. Já segundo Primi et al (2001) o ENEM não evidencia com clareza o que de fato avalia dentro dos modelos contemporâneos da inteligência humana pela ótica da psicometria e psicologia cognitiva.

Sabendo do emprego da evocação dos conteúdos escolares, na cognição da memória, nota-se que, conforme é apontado na questão 65 (ENEM, 2010) e questão 18 (ENEM, 2003), os conteúdos de biologia celular são relembrados para resolver essas questões. Essa evocação de conteúdos ressalta a importância dos conceitos aprendidos no ensino médio para a realização da prova, principalmente na resolução da pergunta 65 , a qual requer memorização de conteúdos específicos, além de exigir a compreensão de conceitos de química.

Sugere que para resolver as questões do ENEM contendo conteúdos da biologia celular, seja necessariamente relembrar conceitos e inferi-los em 
um determinado problema contextualizado com algum fenômeno biológico, necessitando nesse caso principalmente da habilidade cognitiva do raciocínio. Entretanto, das trinta e cinco questões contendo algum conteúdo da biologia celular, dez enfatizam a memorização de conteúdos específicos. Isso certamente contradiz os documentos oficiais desse teste de larga escala, os quais não primam à sobrevalorização de conteúdos escolares.

Assim, compreende-se que para a resolução das perguntas desses conteúdos é necessário além do raciocínio e habilidades como a leitura a interpretação, requer o entendimento ou a evocação de conteúdos particularizados da biologia celular. Sobretudo, ressalta-se que boa parte dos enunciados das vinte e cinco das trinta e cinco perguntas fornecia dados para as resoluções, por exemplo, o enunciado da pergunta 43 (ENEM, 2008), sendo necessário apenas a interpretação e o raciocínio do egresso do ensino médio.

A maioria das perguntas analisadas exigia os conteúdos de forma interdisciplinar. Essa forma de formular conteúdos e questões é privilegiada por textos referenciais do ensino médio, como os PCNEM+ (BRASIL, 2002) e PCN (BRASIL, 1999b), pelos quais o Enem é orientado. A partir dessa fundamentação, foi averiguado que algumas questões estavam associadas aos conteúdos de química, como, por exemplo, as questões 2 (2002) e 40 (2009), que as exigiam habilidades 24 e 25, pertencentes à competência 7. Essa interdisciplinaridade também foi diagnosticada na análise de Silva (2007) para os conhecimentos estatísticos abordados nas questões do ENEM.

\section{CONCLUSÃO}

Conclui-se que as questões do ENEM que exigem a biologia celular procuram não apenas incentivar o reconhecimento dos conteúdos, mas também a análise de problemas. Essas perguntas podem estar contextualizadas com fenômenos biológicos (associados ou não ao cotidiano do estudante do ensino médio) e relacionadas a outras disciplinas de ensino médio. Além disso, algumas dessas questões incentivam, por conseguinte, o raciocínio e a interpretação de problemas fundamentados, mesmo que parcialmente, nas habilidades cognitivas da matriz de referência. Isso demonstra a importância de fundamentar cursos contendo conteúdos de biologia celular no ensino médio baseados nas competências e na resolução de problemas. Na teoria do construtivismo, construir e resolver problemas promove a inquietação no aluno. Esse tipo de construção é necessário para garantir o sucesso da aprendizagem de conteúdos disciplina- 
res, como a Biologia, conforme foi recomendado por Gianotto e Diniz (2010). Essa aprendizagem ativa contribui para que o aluno abandone uma postura passiva de receptor do conhecimento, valorizando a sua construção e evitando a reprodução exclusiva dos conteúdos.

$\mathrm{Na}$ tentativa de avaliar as habilidades e competências no egresso do ensino médio, para o enfoque desses conteúdos, as questões desse exame abordam de forma parcial as habilidades da nova Matriz de referência. Ao associar as habilidades e os conteúdos das perguntas, os fenômenos biológicos nos enunciados não são dimensionados ou ligados às habilidades de forma correta. Além disso, as competências parecem ser muito abrangentes quando são associadas aos conteúdos e habilidades.

A forma de requerer, mesmo que parcial, nas questões as habilidades cognitivas, relacionadas aos conteúdos não fragmentados, mas interligados com outras disciplinas, incentiva a existência de cursos de biologia celular no ensino médio, preocupados não somente com o ensino de conceitos, mas com uma aprendizagem que exige a integração dos conteúdos, a qual pode ser abordada em um fenômeno da natureza. Esse fenômeno, que pode estar na forma de um problema contextualizado com a realidade do egresso do ensino médio, exige habilidades, como o raciocínio, além do entendimento de diversas áreas do conhecimento. Cabe salientar que a contextualização de conceitos com fenômenos da natureza, associado ao cotidiano do aluno, foi recomendada por Macedo (2005) na disciplina escolar de Ciência.

Diante dos resultados apresentados por Santos e Cortelazzo (2010) - os quais diagnosticaram que, no curso de biologia celular do ensino médio de algumas escolas públicas do Estado de São Paulo, os conteúdos eram reduzidos, fragmentados e não havia o constante incentivo da resolução de problemas -, torna-se importante promover a renovação contínua dos cursos de biologia celular, baseada na aprendizagem ativa e efetiva, abordando a resolução de problemas de fenômenos da natureza, principalmente aqueles contextualizados com a realidade do aluno. Esse tipo de aprendizagem pode ser relevante para auxiliar na caracterização do ensino médio, o qual apresenta uma falta de finalidade que ora aborda um extenso conteúdo, atendendo a preparação para a vida universitária e ora contribui para a formação do cidadão crítico e integrado ao conhecimento e à utilização das tecnologias. Sobre os conteúdos reduzidos e fragmentados, o aluno não consegue integrar conceitos e assim a aprendizagem torna-se curta, ou seja, o estudante apenas lembra esses conceitos, em um dado momento, por meio da memorização ou reprodução. Sabe-se que, para Trivelato (2005), o ensino da biologia não pode ser compartimentalizado e sem relação entre 
seus conteúdos, uma vez que esse tipo de ensino não auxilia na aprendizagem efetiva e duradoura. No caso da biologia celular, Palmero (2003), afirma que para uma aprendizagem efetiva, há necessidade não somente da integração dos conceitos, mas compreender a célula como fenômeno vivo e presente na realidade dos alunos, distanciando-se do conceito proposto em muitos livros didáticos do ensino médio, que reconhecem a célula como estrutura estática.

A despeito do ENEM, embora se constituir como um exame classificatório e de verificação do conhecimento, o modo como às questões são formuladas traz apontamentos e possibilidades que podem promover a mediação da aprendizagem da biologia celular. Isto é, se essas perguntas forem associadas às habilidades cognitivas e não promoverem apenas o reconhecimento de conteúdos específicos e fragmentados. Nessa promoção, tendo como referência, o exame não sobrevaloriza a memorização de conceitos e incentiva a resolução de problemas contendo fenômenos biológicos, principalmente aqueles relacionados ao cotidiano dos estudantes. Em alguns testes, a memorização é evocada, no entanto não é posta de forma fragmentada, a maneira como o exercício é formulado contribui para que o aluno tenha uma interação do que anteriormente foi aprendido, o que certamente contribui para o desenvolvimento da aprendizagem efetiva.

\section{REFERÊNCIAS}

AMORIM, L. D. Estratégias utilizadas por estudantes na resolução de questões do Exame Nacional do Ensino Médio (ENEM). 2009. 63f. TCC (Licenciatura em Matemática) - Instituto de Matemática, Universidade Federal do Rio Grande do Sul, Porto Alegre, 2009.

BRASIL. Ministério da Educação. Secretaria de Educação Média e Tecnológica. Exame Nacional do Ensino Médio-ENEM: documento básico. Brasília: INEP, 1999a.

BRASIL. Ministério da Educação. Secretaria de Educação Média e Tecnológica. PCNEM - Parâmetros curriculares nacionais para o ensino médio: ciências da natureza, matemática e suas tecnologias. Brasília: MEC,1999b. 
BRASIL Ministério da Educação. Secretaria de Educação Média e Tecnológica. PCN+ Ensino médio: orientações educacionais complementares aos parâmetros curriculares nacionais - ciência da natureza, matemática e suas tecnologias. Brasília: MEC, 2002.

BRASIL. Ministério da Educação. Secretaria de Educação Média e Tecnológica. Exame Nacional do Ensino Médio-ENEM: documento básico. Brasília: INEP, 2000.

BRASIL. Ministério da Educação. Secretaria de Educação Média e Tecnológica. Exame Nacional do Ensino Médio-ENEM: documento básico. Brasília: INEP, 2002.

BRASIL. Ministério da Educação. Secretaria de Educação Média e Tecnológica. Matriz de referência para o ENEM. Brasília: INEP, 2009.

BRITO, M. R. F. et al. Exames nacionais: uma análise do ENEM aplicado à matemática. Avaliação, Campinas, v. 5, n. 4, p. 45-53, 2000.

CAVALCANTE, L. P. F. et al. ENEM 2005: pressupostos teóricos, desenho metodológico e análise dos resultados. Revista de Ciências Humanas, Florianópolis, v. 6, n. 2, p. 309-319, 2006.

CORTELAZZO, Â. L. Utilização do ENEM pelas universidades estaduais paulistas: abordagem quantitativa da abrangência do exame e desempenho dos egressos de escolas públicas e privadas de ensino médio. Avaliação e Políticas Públicas em Educação, Rio de Janeiro, v. 11, n. 39, p. 36-43, 2003.

FINI, M. E. Erros e acertos na elaboração de itens para a prova do ENEM. In: BRASIL. Ministério da Educação. Secretaria de Educação Média e Tecnológica. ENEM: fundamentação teórica e metodológica. Brasília: INEP, 2005.

FRANCO JUNIOR, F. C. J. Avaliação em larga escala da educação básica: da relevância aos desafios. In: FREITAS, L. C.; BERTAGNA, R. H.; MALAVAZI, S. Avaliação: desafios e novos tempos. Campinas: Komedi, 2003.

GIANOTTO, D. E. P.; DINIZ, R. E. S. Formação inicial de professores de Biologia: a metodologia colaborativa mediada pelo computador e a aprendizagem para a docência. Ciência \& Educação, Bauru, v. 16, n. 3, p. 631-648, 2010. 
GOMES, C. M. A. Uma análise dos fatores cognitivos mensurados pelo Exame Nacional do Ensino Médio (ENEM). 2005. 315f. Tese (Doutorado em Educação) - Faculdade de Educação, Universidade Federal de Minas Gerais, Belo Horizonte, 2005.

GOMES, C. M. A.; BORGES, O. Propriedades psicométricas do conjunto de testes da habilidade visuo espacial. Psico-USF, Itatiba, v. 14, n. 1, 2009.

KITCHEN, E. et al. The development and application of affective assessment in an upper-level cell biology course. Journal of Research in Science Teaching, Michigan, v. 44, n. 8, 2007. p. 1057-87. Disponível em: $<$ http://onlinelibrary.wiley.com/doi/10.1002/tea.20188/pdf $>$. Acesso em: 20 jan. 2008.

MACEDO, L. Eixos teóricos que estruturam o ENEM: conceitos principais, competências e habilidades, situação-problema como avaliação e como aprendizagem, propostas para pensar sobre situações-problema a partir do ENEM. In: BRASIL. Ministério da Educação. Secretaria de Educação Média e Tecnológica. Seminário do Exame Nacional do Ensino Médio, Brasília: INEP, 1999.

MACEDO, E. Esse corpo das ciências é o meu? In: MARANDINO, M. et al. Ensino de biologia: conhecimentos e valores em disputa. Niterói: EdUFF, 2005 .

MACHADO, N. J. Interdisciplinaridade e contextualização no Exame Nacional do Ensino Médio In: BRASIL. Ministério da Educação. Secretaria de Educação Média e Tecnológica. ENEM: fundamentação teórica e metodológica. Brasília: INEP, 2005.

MILDNER, T.; SILVA, A. O ENEM como forma alternativa ou complementar aos concursos vestibulares no caso das áreas de conhecimento "língua portuguesa e literatura": relevante ou passível de refutação.

Avaliação, Campinas, v. 7, n. 2, p. 49-79, 2002a.

MILDNER, T.; SILVA, L. N. O ENEM é alternativa ao vestibular? O caso da área de química. Avaliação, Campinas, v. 7, n. 3, p. 103-152, 2002 b.

MINHOTO, M. A. P. Da disseminação da cultura de avaliação educacional: estudo sobre a institucionalização do ENEM. Poiésis, Tubarão, v. 1, n. 1, p. 68-85, 2008. 
PALMERO, M. L. R. La célula vista por el alumnado. Ciencia \& Educação, Bauru, v. 9, n. 2, p. 229-246, 2003.

PERRENOUD, P. Práticas pedagógicas, profissão docente e formação: perspectivas sociológicas. 2. ed. Lisboa: Dom Quixote, 1997.

PERRENOUD, P. 10 novas competências para ensinar. Porto Alegre: Artes Médicas Sul, 2000.

PRIMI, R. et al. Competências e habilidades cognitivas: diferentes definições dos mesmos construtos. Psicologia, Brasília, v. 17, n. 2, p. 151-159, 2001.

SANT'ANNA, I. M. Conceitos. In: . Por que avaliar? Como avaliar?: critérios e instrumentos. Rio de janeiro: Vozes, 1995.

\section{SANTOS, J. S. Avaliação dos conteúdos de biologia celular no ensino} médio: estudo de caso sobre a prática docente e sua relação com exames de ingresso no ensino superior. 2008. 153f. Dissertação (Mestrado em Biologia Celular e Estrutural) - Instituto de Biologia, Universidade Estadual de Campinas, Campinas, 2008.

SANTOS, J. S.; CORTELAZZO, A. L. Avaliação dos conteúdos de biologia celular no ensino médio: estudo de caso da pratica docente e sua relação com o exame vestibular UNICAMP. Educere, Umuarama, v. 10, n. 1, p. 1-30, 2010. Disponível em: <http://revistas.unipar.br/educere/article/ viewFile/3231/2251>. Acesso em: 20 dez. 2010.

SASS, O.; MINHOTO, M. A. P. Indicadores e educação no Brasil: a avaliação como tecnologia. Constelaciones, Madri, n. 2, p. 232-252, dez. 2010.

SOARES, S. S. D.; NASCIMENTO, P. A. M. M. Evolução do desempenho cognitivo do Brasil de 2000 a 2009 face aos demais países. Brasília: IPEA, 2011.

SILVA SOARES, G. F. O ENEM e a USP. Jornal da USP, São Paulo, p. 2, 12 maio 1999.

SILVA, J. C. Conhecimentos estatísticos e os exames oficiais: SAEB, ENEM e SARESP. 2007. 105 f. Dissertação (Mestrado Educação em Matemática) - Pontíficia Universidade Católica de São Paulo, São Paulo, 2007. 
TRIVELATO, S. L. F. Que corpo/ser humano habita nossas escolas? In: MARANDINO, M. et al. Ensino de biologia: conhecimentos e valores em disputa. Niterói: EdUFF, 2005.

ZANCHET, B. M. B. A. O exame nacional do ensino médio - o ENEM uma auto-avaliação para quem? Avaliação, Campinas, v. 8, n. 3, p. 247-269, 2003. 